\title{
Story retelling and verbal working memory in people with aphasia
}

\author{
Hyunsoo Yoo ${ }^{1}$, Malcolm R. McNeil ${ }^{2,3}$ \\ ${ }^{1}$ Baylor University, Waco, $T X_{;}{ }^{2}$ University of Pittsburgh, Pittsburgh, PA; ${ }^{3}$ VA Pittsburgh Healthcare System, Pittsburgh, PA, USA
}

Purpose: This study explored the relationship between story retelling and verbal working memory (VWM) in people with aphasia due to left-hemisphere damage (PWA), people without aphasia with left-hemisphere damage (LHD) and normal healthy controls (HC).

Methods: Fifteen age-matched HC and fifteen of each, PWA and LHD participants were enrolled and their performances on the Story Retell Procedure (SRP) and WM tasks were compared with tests of association and tests of difference. The experimental tasks included the SRP, where each participant retold three stories, and "percent information units per minute (\%IU/Min)" was calculated as an SRP-performance measure. The Alphabet span task served as a WM measure based on a principle component analysis.

Results: All Bonferroni-corrected pairwise comparisons were significant, with the PWA group producing the lowest \%IU/Min, followed by the LHD group and then the HC group. The Bonferroni-corrected VWM score differences were also significant across the three groups, with the PWA group producing significantly lower \%IU/Min than both other groups. The difference between the LHD and HC groups was not significant. The correlations between the \%IU/Min and WWM score were all significant and ranged from 0.50 to 0.75 among the three groups.

Conclusions: SRP performance yielded a continuum across the three groups, suggesting that SRP performance in PWA is consistent with a combination of both aphasia-related and brain damage-related deficits.

Keywords: Story Retelling, Verbal Working Memory, Aphasia, Recovery

\section{INTRODUCTION}

Story retelling (SR) in people with aphasia (PWA) has been investigated from multiple perspectives. McNeil et al. $[1,2]$ found that the \%IU/Min metric is more sensitive than \%IU in differentiating PWA from healthy controls (HC). SR has also been investigated from a resource-allocation perspective, employing visual-manual tracking under dualtask conditions [3-5], relative to primacy/recency serial position effects [6] and shortterm memory demands [7-10] in normal aging and child language disorders. Montgomery, Polunenko, and Marinellie [9] found that resource capacity is importantly implicated in children's ability to understand spoken narrative. Gabig [8] claimed that SR requires significant VWM demands and also relates to processing linguistic information, cognitive organization, and regulatory control. Gabig [8] speculated that difficulty in SR might be due to either primary or secondary linguistic representation deficits required for simultaneous processing and recall rather than impairment in VWM capacity per se.

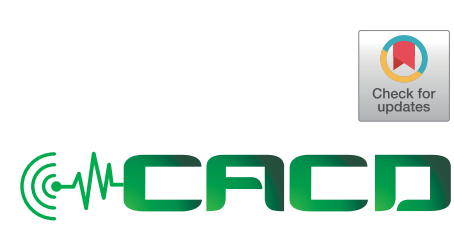

Received: November 1, 2019 Revision: December 20, 2019 Accepted: December 22, 2019

\section{Correspondence: \\ Hyunsoo Yoo}

Department of Communication Science and Disorders, Robbins College of Health and Human Sciences, One Bear Place \#97332, Waco TX, Baylor University, USA Tel: +1-254-710-2587

Fax: +1-254-710-2590

E-mail: hyunsooyoo@gmail.com

(C) 2019 The Korean Association of SpeechLanguage Pathologists

This is an Open Access article distributed under the terms of the Creative Commons Attribution NonCommercial License (http://creativecommons.org/ licenses/by-nc/4.0/) which permits unrestricted noncommercial use, distribution, and reproduction in any medium, provided the original work is properly cited. 
Significant and reliable differences have been found between PWA and age-matched HC on the SR tasks. Lower SR performance in PWA compared to that of HC might not indicate that the presence of aphasia is responsible for the difference. It is unclear whether these differences are attributable to the presence of aphasia or more generally to the presence of left-hemisphere damage (LHD). It is therefore important to compare SR performance between people with and without aphasia after LH stroke as well as with performance of HC.

In addition to examining differences between groups, the relationship between SR and VWM has been inadequately investigated in PWA. While Brodsky et al. [6] examined the primacy/recency serial position effects in SR in PWA, which involve components of VWM; specific components of VWM, such as maintaining, manipulation, and updating have not been investigated. Gabig [8] used three measures of VWM (nonword repetition, digit span, and sentence imitation) in the SR study of children with autism. These VWM tasks engage short-term memory (STM), including rehearsal, but do not engage the executive components of VWM such as updating and manipulation $[11,12]$. Updating is a crucial function in SR in order to remember passage details within the story. The manipulation part of VWM is also necessary for SR in order to integrate information and make appropriate inferences about the story's meaning.

The aims of this study were to explore whether the SR and VWM performances are aphasia-specific or more generally due to LHD, and to examine the relationship between the SR and VWM performances within the three groups. In order to address these issues, significant differences between the two groups of volunteers with left hemisphere damage secondary to stroke with and without aphasia, and the HC group were compared on the SRP and a measure of VWM. Correlations were computed between measures on the SRP and VWM for each group. It was hypothesized that strong correlations would exist between SR and VWM performances and that these correlations would be strongest in the PWA group, followed by the LHD group, and finally the HC group.

\section{METHODS}

\section{Participants}

Sixty participants were enrolled in this study: 1) 15 individuals with LHD after a stroke that resulted in aphasia (PWA group), 2) 15 individuals with LHD after a stroke that are without aphasia (LHD group), and 3) $30 \mathrm{HC}$ without brain damage
(HC group). Age and years of education were not significantly different among the three groups. Age and education information for the three groups are presented in Table 1. The study was approved by the Institutional Review Board (IRB) of the University of Pittsburgh (IRB\# PRO15120107). Informed consent was obtained from all patients before inclusion in the study. Participant recruitment and enrollment were based on the following resources: 1) the University of Pittsburgh Research Participant Registry (https://www.researchregistry. pitt.edu/Researchers.shtml), 2) the Western Pennsylvania Patient Registry (http://www.wppr.pitt.edu/wppr_research. html) and 3) the Bethel Park community center.

All participants met the following screening criteria: (a) native American English speaker and (b) at least 8 years of education, determined by a self-reported questionnaire. Participants were also assessed for (c) 20/40 or better binocular acuity by the reduced Snellen chart. (d) greater than 0.70 ratio (the delayed recall/immediate language recall $\times 100)$ from the $A s$ sessment Battery of Communication in Dementia (ABCD) [13]. The HC participants self-reported a negative history for neurologic, limb motor, psychiatric, visual, speech/language, or reading impairments.

The demographic and descriptive evidence for all participants in the PWA and LHD groups included evidence of a unilateral LH lesion from medical history and/or brain imaging. Appendices 1-3 provide descriptive information for all participants in this study.

The PWA and LHD groups were examined for aphasia using the Comprehensive Aphasia Test (CAT) [14]. All individuals with aphasia met the definition of aphasia [15] and the following inclusion criteria: deficit 1) on at least one subtest (determined by pre-established cutoff scores for each subtest in the CAT) or 2) on the summary score from at least two different language modalities (listening, speaking, reading, and writing) on the test. Appendices 4-7 provide the CAT scores and the $t$ and $z$ scores for the CAT subtests for the PWA and LHD groups.

Table 1. Descriptive Information of Participants

\begin{tabular}{lcc}
\hline Groups & Age & Years of Education \\
\hline PWA & $64.2(8.89)$ & $15.4(1.18)$ \\
LHD & $60.87(14.63)$ & $14.7(2.4)$ \\
HC & $64.4(5.32)$ & $16.7(2.2)$ \\
\hline
\end{tabular}

PWA, people with aphasia; LHD, people without aphasia with lefthemisphere damage; $\mathrm{HC}$, healthy controls. 


\section{Materials \& Procedures}

\section{Experimental Tasks}

Each participant performed three SRP stories (Loan, Gas, and Library) [16], and the \%IU/Min was calculated based on the average of the three stories. The Digit-span forward [17], Sentence span [18], Subtract-2 span tasks [19], and Alphabet span task [19] were included initially for WM measures, and the Alphabet span task was eventually selected as the WM task based on the results of a principle component analysis (PCA).

\section{Story Retelling}

Each participant listened to each of the three stories from one form of the SRP battery, and retold the story, in their own words, to the examiner. The retelling from each participant was recorded and scored for \%IU/Min using the standardized score sheet, by a native English-speaking graduate student majoring in speech and language pathology.

\section{Working Memory (WM)}

The Digit-span forward [17] and Sentence span [18], Subtract-2 span [19], and Alphabet span tasks [19] were included as short-term or working memory tasks. The forward-digit span task was presented using E-Prime 1.0 [20]. For this task, participants listened to a series of digits and pointed to those digits in order, selected from nine digits displayed on the computer screen. The sentence span task was also presented using E-Prime 1.0. For this task, participants read each sentence at each span and were requested to remember the last word of the sentence. Participants also responded to a question about the sentences' meaning. The number of words recalled indexed the sentence span. The subtract- 2 span task was presented by the examiner. Participants listened to a series of digits and repeated them to the examiner after subtracting number 2 from each of the digits they heard. For example, if they heard 4-2, they answered with 2-0 after subtracting 2 from each number. The alphabet span task was presented using a recording of the examiner's voice. In this task, participants listened to a series of words and were required to reorder them in alphabetical order. For example, if they heard "hat-cat," a correct response would be "cat-hat". The number of the words presented increased across spans.

\section{Data Analysis}

Based on the principle component analysis (PCA), the Alphabet span task was selected as the VWM task. IBM SPSS Statistics 24 was employed for all statistical analyses. An analysis of variance (ANOVA) was computed comparing SRP (\% IU/Min) and VWM measure between and within the three groups. Bonferroni post-hoc comparisons were used to correct $p$-values that were adopted for this study $(p=.016)$. Pearson correlations were computed to examine the association between SRP and VWM.

\section{RESULTS}

\section{PCA Results}

A PCA with varimax rotation was performed for the WM tasks in order to identify those with the greatest shared variance and interrelationships among tasks. The task with the highest value was selected, and it was found that the Alphabet span task's eigenvalues explained $76 \%$ of variance. Therefore, the Alphabet span task was selected as the most representative WM task. Table 2 summarizes the coefficients derived from the PCA rotated component matrix.

\section{ANOVA Results}

The results of the ANOVA for SRP performance (\%IU/Min) revealed a significant difference across the three groups (see Table 3) $(F(2,57)=62.01, p=0.000)$. Bonferroni post-hoc comparisons indicated that the PWA group produced significantly fewer \%IU/Min $(M=9.8, S D=1.87)$ than the HC group $(M=$ $34.5, S D=1.32$ ) and significantly fewer than the LHD group $(M=27.3, S D=1.87)$. The LHD group's \%IU/Min $(M=27.3$, $S D=1.87$ ) was also significantly lower than the HC group's $\% \mathrm{IU} / \operatorname{Min}(M=27.3, S D=1.87)$.

The results of the VWM measure also revealed significant

Table 2. Coefficients derived from the PCA rotated component matrix

\begin{tabular}{lcc}
\hline WM tasks & Eigenvalues & Initial Eigenvalues \% of Variance \\
\hline Alphabet & 0.857 & 76.254 \\
Subtract-2 & 0.792 & 10.991 \\
Sentence & 0.727 & 8.949 \\
Forward digit & 0.675 & 3.836 \\
\hline
\end{tabular}

Table 3. Results of Story Retelling and VWM measure

\begin{tabular}{lcc}
\hline Groups & Story Retelling (\%IU/Min) & WM (Alphabet Span) \\
\hline PWA & $9.8(1.87)$ & $1.97(.23)$ \\
LHD & $27.3(1.87)$ & $3.6(.23)$ \\
HC & $34.5(1.32)$ & $4.23(.16)$ \\
\hline
\end{tabular}

PWA, people with aphasia; LHD, people without aphasia with lefthemisphere damage; $\mathrm{HC}$, healthy controls. 
Table 4. Correlation Coefficient $r$ from Pearson Correlation Analysis between Story Retelling Procedure and VWM measure scores

\begin{tabular}{lccc}
\hline Groups & PWA & LHD & NC \\
\hline WWM & 0.748 & 0.620 & 0.503 \\
& $(p=.001)$ & $(p=.014)$ & $(p=.005)$ \\
\hline
\end{tabular}

VWM, verbal working memory.

differences among the three groups $(F(2,57)=34.01, p=0.000)$. The VWM scores in the PWA group $(M=1.97, S D=0.23)$ were significantly lower $(p=0.000)$ than those in the HC group $(M=$ 4.23, $S D=0.16$, and significantly lower $(p=0.000)$ than those in the LHD group ( $M=3.6, S D=0.23$. However, the VWM scores in the LHD group did not differ significantly $(p=0.075)$ from those of the HC group.

\section{Pearson Correlation Results}

Correlations between the SRP and VWM scores are summarized in Table 4 . The correlations were significant and moderate to high across the three groups. The highest correlation was evidenced in the PWA group $(r=0.748 p=0.001)$, followed by that in the LHD group $(r=0.620, p=0.014)$ and then in the HC group $(r=0.503, p=0.005)$.

\section{DISCUSSION}

The first goal of this study was to examine whether the PWA group exhibited aphasia-specific deficits in SR and VWM that taxes updating and computation functions compared to the LHD and HC groups. The second goal examined the association between SR and VWM within each group.

The PWA group's SR performance was significantly lower than the other two groups with the LHD group performing intermediary between the aphasic and healthy control groups. Because the LHD non-aphasic group differed significantly from the healthy controls and the PWA group, who shared a left hemisphere lesion with the LHD group, it is proposed that the SR deficits in PWA result from combined aphasia-related and brain damage-related deficits rather than aphasia-specific deficits. More specifically, the difference in performance between the PWA and LHD groups suggests an additive effect of aphasia beyond the lesion on SRP performance. Correspondingly, the significantly lower performance by the LHD group compared to the HC group is consistent with a strokeinduced brain damage-related deficit. Therefore, SR deficits in PWA are consistent with a combined aphasia-related and brain damage-related effect.
There were also group differences in VWM performance. The PWA group had significantly lower scores than both the LHD and HC groups. However, the performance of the LHD group was not significantly different from the HC group. Unlike performance on the SRP task, VWM performance in PWA appear to be aphasia-specific rather than due to combined stroke-induced aphasia and brain damage effects.

The relationship between the SR and VWM performances across the groups revealed the strongest correlation in the PWA group, followed by the LHD group followed by the weakest, but still significant, correlation between SR and VWM in the HC group. Consistent with the Brodsky et al. study [6], and adding to memorial requirements of the SRP task, this pattern indicates that VWM, as measured by these working memory tasks, is reliably related to SR performance. This becomes more evident as both SR and VWM performance is less efficient or more impaired. More specifically, these results suggest that the underlying cognitive operations required for these VWM tasks are related to and predictive of SR performance in PWA. This might be because SR requires the updating and/or computing components of VWM, which are unique and attributable to the presence of aphasia.

The pattern of SR performance across the groups suggests that SRP deficits are not specific to PWA. The significant difference in SRP performance between the LHD and HC participants does support the sensitivity of the task for indexing the presence of brain damage with or without the presence of aphasia. The establishment of cutoff scores on this specific task is required in order to use it as a diagnostic criterion for the presence or absence of aphasia. SRP performance does, however, provide a useful measure of overall language performance and can serve as a measure useful for targeting treatment and for establishing both severity of deficits and as a tool for indexing recovery from brain damage and aphasia.

Gabig [8] concluded that story retelling makes considerable demands on VWM as well as on other cognitive processes such as cognitive organization and regulatory control. VWM measures may supplement measures of language performance in the diagnosis and evaluation of brain damage and aphasia. The results of the current study suggest that the presence of language deficits following stroke is not unique to PWA. The degree to which VWM is required to build linguistic representations in PWA and is the source of their connected language performance deficits, as measured by tasks such as the Story Retell Procedure, remains an important area for future research. 


\section{CONCLUSIONS}

The current study examined associations and differences in story retelling and verbal working memory performance in PWA, LHD, and HC groups. It was found that only story retelling, as measured by percent information units per minute differed significantly among the three groups. Verbal working memory performance was significantly poorer for the PWA group than the other two groups, who did not differ from each other. The correlations between the story retelling and verbal working memory ranged from moderate to strong within the three groups.

The present findings are interpreted as evidence that story retelling performance in PWA is impaired by both aphasia-related and brain damage-related deficits and that SR deficits in PWA might be caused by both deficits in processing linguisticspecific rules and representations and by additional limitations in cognitive processes involved in verbal working memory such as maintenance, manipulation, and especially updating processes.

\section{REFERENCES}

1. McNeil MR, Doyle PJ, Fossett TRD, Park GH, Goda AJ. Reliability and concurrent validity of the Percent Information Unit (\%IU) scoring metric for the RAPP Story Retelling Procedure. Aphasiology, 2001;15:991-1006.

2. McNeil MR, Doyle PJ, Park GH, Fossett TRD, Brodsky MB. Increasing the sensitivity of the Story Retell Procedure for the discrimination of normal elderly participants from person with aphasia. Aphasiology, 2002;16:815-822.

3. McNeil MR, Doyle PJ, Hula WD, Rubinsky HJ, Fossett TRD, Matthews CT. Using resource allocation theory and dual-task methods to increase the sensitivity of assessment in aphasia. Aphasiology, 2004;18:521-542.

4. McNeil MR, Matthews CT, Hula WD, Doyle PJ, Rubinsky HJ, Fossett TRD. A dual task tool for quantifying normal comprehension of aphasic connected speech production: A constructive replication. Aphasiology, 2005;19:473-484.

5. McNeil MR, Matthews CT, Hula WD, Doyle PJ, Fossett TRD. Effects of visual manual tracking under dual-task conditions on auditory language comprehension and story retelling in persons with aphasia, Aphasiology, 2006;20:167-174.

6. Brodsky MB, McNeil MR, Doyle PJ, Fossett TRD, Timm NH, Park
GH. Auditory serial position effects in story retelling for normal adult subjects and person with aphasia. Journal of Speech, Language and Hearing Research, 2003;46:1124-1137.

7. Barber SJ, Mather M. How retellings shape younger and older adults'memories. Journal of Cognitive Psychology, 2014;26:263279.

8. Gabig CS. Verbal working memory and story retelling in schoolage children with autism. Language, speech, and hearing services in schools, 2008;39:498-511.

9. Montgomery J, Polunenko A, Marinellie S. Role of working memory in children's understanding spoken narrative: A preliminary investigation, Applied Psycholinguistics, 2009;30:485-509.

10. Swinburn K, Baker G, Howard D. CAT: The Comprehensive Aphasia Test. New York: Psychology Press. 2005.

11. Engle RW, Kane MJ, Tuholski SW. Individual differences in working memory capacity and what they tell us about controlled attention, general fluid intelligence, and functions of the prefrontal cortex. In A. Miyake \& P. Shah (Eds.), Models of working memory: Mechanisms of active maintenance and executive control (pp. 102-134). London, England: Cambridge University Press. 1999.

12. Miyake A, Friedman NP, Emerson MJ, Witzki AH, Howerter A, Wager TD. The unity and diversity of executive functions and their contributions to complex "frontal lobe" tasks: A latent variable analysis. Cognitive Psychology, 2000;41:49-100.

13. Bayles KA, Tomoeda CK. Arizona battery for communication disorders of dementia. Pro-Ed. Austin, Texas. 1993.

14. Swanson HL, Zheng XH, Jerman O. Working Memory, Short-Term Memory, and Reading Disabilities: A Selective Meta-Analysis of the Literature. Journal of Learning Disabilities, 2009;42:260-287.

15. McNeil MR, Pratt SR. Defining aphasia: Some theoretical and clinical implications of operating from a formal definition. Aphasiology, 2001;15:901-911.

16. McNeil MR, Sung JE, Yang D, Pratt SR, Fossett TRD, Pavelko S, Doyle PJ. Comparing connected language elicitation procedures in person with aphasia: Concurrent validation of the Story Retell Procedure. Aphasiology, 2007;21:775-790.

17. Martin N, Kohen FP, Kalinyak-Fliszar M. A processing approach to the assessment of language and verbal short-term memory abilities in aphasia. Clinical Aphasiology Conference; Charleston, SC. 2010.

18. Waters GS. Caplan D. The measurement of verbal working memory capacity and its relation to reading comprehension. Quarterly Journal of Experimental Psychology. 1996;49A:51-74.

19. Waters GS, Caplan D. The reliability and stability of operation span measures. Behavioral Research Methods, Instruments \& Computers. 2003;35:550-564.

20. Schneider W, Eschman A, Zuccolott A. E-Prime user's guide. Pittsburgh: Psychology Software Tools Inc. 2002. 
Appendix 1. Demographic and Lesion Information for PWA individuals

\begin{tabular}{|c|c|c|c|c|c|}
\hline Group P = PWA & Age & Gender & Education & РОТ & Lesion Site \\
\hline P1 & 68 & $\mathrm{~F}$ & 14 & $9 y$ & Left CVA \\
\hline P2 & 53 & M & 14 & $7 y$ & Cerebral hemispheres: Periventricular encephalomalacia \\
\hline P3 & 69 & M & 16 & 1 y $10 \mathrm{~m}$ & Cerebral Artery Occlusion, unspecified with cerebral infarction \\
\hline P4 & 69 & M & 14 & $4 y$ & $\begin{array}{l}\text { Left hemorrhagic cerebrovascular accident (CVA): Cerebral artery occlusion with } \\
\text { cerebral infarction }\end{array}$ \\
\hline P5 & 70 & $\mathrm{~F}$ & 16 & 11 y & Left middle cerebral artery cerebrovascular accident (CVA) \\
\hline P6 & 84 & $M$ & 16 & $4 y$ & $\begin{array}{l}\text { Description: Moderately large area of restricted diffusion is seen on the DWI images in } \\
\text { L frontotemporal, temporal, subinsular and basal ganglion regions involving caudate } \\
\text { \& lentiform nuclei. } \\
\text { No hemorrhagic transformation. } \\
\text { Corresponding high FLAIR T2 signal intensity is noted. Some periventricular FLAIR } \\
\text { hyperintensity may represent chronic ischemic changes. Some local mass effect on L } \\
\text { Sylvian fissure but there's no hydrocephalus or gross midline shift. } \\
\text { Affected Lobes: Left temporal, left frontal, left subcortical }\end{array}$ \\
\hline P7 & 53 & $\mathrm{~F}$ & 16 & 10 y $7 \mathrm{~m}$ & $\begin{array}{l}\text { Left CVA: Large area of restricted diffusion identified w/in L MCA destruction. } \\
\text { Predominantly involve the posterior L frontal lobe, anterior left parietal lobe and L } \\
\text { basal ganglia. } \\
\text { There's relative sparing of the anterior L temporal lob } \\
\text { Affected Lobes: left parietal, left frontal, left subcortical } \\
\text { Affected Vasculature: left MC }\end{array}$ \\
\hline P8 & 68 & M & 15 & $5 y 1 m$ & L MCA infarct \\
\hline P9 & 65 & M & 16 & $9 y$ & Left frontal \\
\hline P10 & 69 & M & 18 & 6 y 2 m & Left hemorrhagic cerebrovascular accident: left MCA CVA hemorrhage into infarct \\
\hline P11 & 59 & $\mathrm{~F}$ & 16 & $6 m$ & $\begin{array}{l}\text { Description: Evolving infarction L basal ganglia, corona radiate, centrum, semiovale, } \\
\text { middle frontal gyrus, amygdala. } \\
\text { Focal infarction L parietal lobe. } \\
\text { Edema w/increased mass effect on frontal horn of L lateral ventricle. } \\
\text { No midline shift. } \\
\text { Small foci of petechial hemorrhages w/out a large intraparenchymal hematoma } \\
\text { Affected Lobes: left parietal, left frontal, left subcortical } \\
\text { Affected Vasculature: left MCA }\end{array}$ \\
\hline P12 & 48 & F & 16 & 5 y 2 m & $\begin{array}{l}\text { Description: There's a large area of diffusion restriction in the left parietal and temporal } \\
\text { lobes consistent with acute infarct. There's no hemorrhagic conversion } \\
\text { Affected Lobes: left temporal, left parietal } \\
\text { Affected Vasculature: left MCA }\end{array}$ \\
\hline $\mathrm{P} 13$ & 65 & M & 16 & 3 y 3 m & $\begin{array}{l}\text { Large L MCA stroke } \\
\text { Left MCA }\end{array}$ \\
\hline P14 & 65 & M & 14 & 7 y $1 \mathrm{~m}$ & $\begin{array}{l}\text { L MCA territory infarct } \\
\text { Left MCA }\end{array}$ \\
\hline P15 & 58 & $M$ & 14 & 31 y 6 m & $\begin{array}{l}\text { Left frontoparietal region } \\
\text { Affected Lobes: left frontal, left parietal }\end{array}$ \\
\hline Mean & 64.2 & & 15.4 & & \\
\hline
\end{tabular}


Appendix 2. Demographic and Lesion Information for LHD individuals

\begin{tabular}{|c|c|c|c|c|c|}
\hline $\begin{array}{l}\text { Group } \\
\mathrm{L}=\mathrm{LHD}\end{array}$ & Age & Gender & Education & РОТ & Lesion Site \\
\hline L1 & 57 & $\mathrm{~F}$ & 16 & 11 y 5 m & $\begin{array}{l}\text { Encephalomalacia within the left MCA territory in the left frontal lobe } \\
\text { Affected lobes: Left frontal } \\
\text { Affected Vasculature: Left MCA }\end{array}$ \\
\hline L2 & 76 & $M$ & 15 & 2 y $4 \mathrm{~m}$ & $\begin{array}{l}\text { Description: Left periventricular; posterior temporal; basal ganglia } \\
\text { Affected Lobes: Left temporal, left subcortical }\end{array}$ \\
\hline L3 & 80 & $M$ & 14 & 1 y 8 m & $\begin{array}{l}\text { Acute ischemic stroke } \\
\text { Description: Restricted diffusion L insular/left basal ganglia/corona radiate plus rounded area } \\
\text { of restricted diffusion in the left lateral aspect temporal lab. } \\
\text { These findings are consistent with an acute infarct in the left MCA distribution. } \\
\text { Other tiny punctate foci of restricted diffusion in the brain parenchyma probably procedure } \\
\text { related. } \\
\text { Affected Lobes: left temporal, left subcortical, left other } \\
\text { Affected Vasculature: Left MCA }\end{array}$ \\
\hline L4 & 49 & $\mathrm{~F}$ & 14 & $11 y$ & $\begin{array}{l}\text { Acute ischemic stroke } \\
\text { Description: infarct L basal ganglia } \\
\text { Affected Lobes: Left subcortical }\end{array}$ \\
\hline L5 & 26 & F & 17 & $2 y$ & $\begin{array}{l}\text { Description: Scattered small foci w/in L MCA distribution, especially L precentral gyrus, are } \\
\text { seen with restricted diffusion on D-W I, and abnormal T2 prolongation on T2 FLAIR } \\
\text { concerning for subacute infarcts, likely associated with/L MCA distribution emboli. } \\
\text { Surrounding small areas of localized edema around these infarcts are noted, without mass } \\
\text { effect or middle shift. } \\
\text { No evidence of hemorrhage on the blood sensitive sequences } \\
\text { Affected lobes: left frontal, left other } \\
\text { Affected vasculature: left MCA }\end{array}$ \\
\hline L6 & 80 & $\mathrm{~F}$ & 16 & 1 y $8 \mathrm{~m}$ & $\begin{array}{l}\text { Acute ischemic stroke } \\
\text { Description: There are several tiny acute foci of stroke in the distribution suggested by the } \\
\text { CTA, in the posterior left MCA distribution. } \\
\text { There's no evidence of hemorrhagic transformation } \\
\text { Affected lobes: left other } \\
\text { Affected Vasculature: left MCA }\end{array}$ \\
\hline L7 & 61 & M & 15 & 12 y 1 m & $\begin{array}{l}\text { Description: Ventricles, cortical sulci and basilar cisterns are normal. Restricted diffusion } L \\
\text { frontoparietal cortical sulci expending into insular region consistent w/ acute infarct. } \\
\text { Diffusion restriction in region of } L \text { caudate nucleus \& L basal ganglia. Distribution of LMCA. } \\
\text { No midline shift. No intracranial hemorrhage. Posterior fossa is unremarkable. } \\
\text { No pathologic extra-axial collections. } \\
\text { Affected Lobes: Left parietal, left frontal, left } \\
\text { Affected Vasculature: left MCA }\end{array}$ \\
\hline L8 & 46 & M & 13 & $11 \mathrm{~m}$ & $\begin{array}{l}\text { Acute ischemic stroke } \\
\text { Description: Subacute infarcts of } L \text { basal ganglion, } L \text { subsegmental frontal cortex, } \\
\& L \text { caudate, w/a small amount of petechial hemorrhagic component. } \\
\text { Small amount of subarachnoid blood in } L \text { Sylvian fissure } \\
\text { Affected Lobes: left frontal, left subcortical, left other } \\
\text { Affected Vasculature: left MCA }\end{array}$ \\
\hline L9 & 53 & $M$ & 12 & $3 m$ & $\begin{array}{l}\text { Description: Small focal areas of decreased diffusion identified within the left parietal } \\
\text { occipital region including subcortical white matter and centrum semiovale corresponding to } \\
\text { the left ACA/MCA watershed distribution } \\
\text { Affected Lobes: left occipital, left parietal, left other } \\
\text { Affected Vasculature: left ACA, left MCA }\end{array}$ \\
\hline
\end{tabular}


Appendix 2. Continued

\begin{tabular}{|c|c|c|c|c|c|}
\hline $\begin{array}{l}\text { Group } \\
\mathrm{L}=\mathrm{LHD}\end{array}$ & Age & Gender & Education & РОТ & Lesion Site \\
\hline L10 & 69 & $\mathrm{~F}$ & 20 & $3 m$ & $\begin{array}{l}\text { Description: Areas of infarction involving the left MCA territory, predominantly within the bas- } \\
\text { al ganglia and caudate regions } \\
\text { Affected Lobes: Left subcortical } \\
\text { Affected Vasculature: Left MCA }\end{array}$ \\
\hline L11 & 67 & $\mathrm{~F}$ & 12 & 5 y $2 m$ & $\begin{array}{l}\text { Acute ischemic stroke } \\
\text { Description: Patchy areas of restricted diffusion w/in } L \text { cerebral hemisphere in parts of MCA } \\
\text { territory including in } L \text { frontal \& parietal lobes involving the basal ganglia in L perisylvian re- } \\
\text { gion consistent with area of recent infarction } \\
\text { Affected Lobes: Left subcortical, left frontal, left parietal } \\
\text { Affected vasculature: Left MCA }\end{array}$ \\
\hline $\mathrm{L} 12$ & 76 & $\mathrm{~F}$ & 12 & $7 y$ & Life middle cerebral artery (MCA) disruption \\
\hline L13 & 59 & M & 15 & $3 m$ & $\begin{array}{l}\text { Acute ischemic stroke } \\
\text { Description: Patchy areas of restricted diffusion w/areas of core infarction involving } L \text { posterior } \\
\text { frontal periventricular white matter extending into } L \text { corona radiate, } L \text { insular cortex and por- } \\
\text { tions of } L \text { frontal \& temporal lobe bordering } L \text { Sylvian fissure. } \\
\text { Affected Lobes: Left temporal, left frontal, left others } \\
\text { Affected vasculature: Left MCA }\end{array}$ \\
\hline L14 & 60 & $\mathrm{~F}$ & 12 & $16 y$ & $\begin{array}{l}\text { Left MCA territory: Multiple embolic occlusions in distal branches of ACA, MCA and PCA } \\
\text { branches } \\
\text { Description: L medial frontal, L posterior frontal, L parietal } \\
\text { Affected Lobes: Left frontal } \\
\text { Left parietal }\end{array}$ \\
\hline L15 & 54 & M & 18 & 6 y $8 \mathrm{~m}$ & $\begin{array}{l}\text { Description: Acute lacunar nonhemorrhagic infarct w/in posterior } L \text { parietal cortical region } \\
\text { seen as a restriction defect on the diffusion \& ADC mapping imaging. } \\
\text { This measures } 7.5 \mathrm{~mm} \text {. } \\
\text { No other areas of signal abnormality are seen in the gray and white matter regions } \\
\text { Affected Lobes: Left parietal } \\
\text { Mean }\end{array}$ \\
\hline
\end{tabular}


Appendix 3. Demographic Information for NHC individuals

\begin{tabular}{|c|c|c|c|}
\hline Group & Age & Gender & Education \\
\hline 1 & 82 & $\mathrm{~F}$ & 18 \\
\hline 2 & 59 & $\mathrm{~F}$ & 18 \\
\hline 3 & 72 & $M$ & 16 \\
\hline 4 & 59 & $\mathrm{~F}$ & 18 \\
\hline 5 & 67 & $\mathrm{~F}$ & 17 \\
\hline 6 & 61 & $\mathrm{~F}$ & 13 \\
\hline 7 & 60 & $\mathrm{~F}$ & 18 \\
\hline 8 & 69 & $\mathrm{~F}$ & 18 \\
\hline 9 & 62 & $\mathrm{~F}$ & 13 \\
\hline 10 & 59 & $\mathrm{~F}$ & 12 \\
\hline 11 & 67 & $\mathrm{~F}$ & 18 \\
\hline 12 & 70 & $\mathrm{~F}$ & 18 \\
\hline 13 & 65 & $M$ & 16 \\
\hline 14 & 57 & $\mathrm{~F}$ & 14 \\
\hline 15 & 76 & $M$ & 16 \\
\hline 16 & 57 & $\mathrm{~F}$ & 22 \\
\hline 17 & 60 & $\mathrm{~F}$ & 16 \\
\hline 18 & 76 & $\mathrm{~F}$ & 16 \\
\hline 19 & 55 & $\mathrm{~F}$ & 16 \\
\hline 20 & 59 & $\mathrm{~F}$ & 13 \\
\hline 21 & 58 & $\mathrm{~F}$ & 16 \\
\hline 22 & 62 & $\mathrm{~F}$ & 18 \\
\hline 23 & 69 & $\mathrm{~F}$ & 18 \\
\hline 24 & 64 & $\mathrm{~F}$ & 20 \\
\hline 25 & 65 & $\mathrm{~F}$ & 15 \\
\hline 26 & 65 & $M$ & 16 \\
\hline 27 & 62 & $\mathrm{~F}$ & 16 \\
\hline 28 & 71 & $M$ & 18 \\
\hline 29 & 62 & $\mathrm{~F}$ & 18 \\
\hline 30 & 62 & $M$ & 19 \\
\hline Mean & 64.4 & & 16.67 \\
\hline
\end{tabular}


Appendix 4. CAT Scores for PWA Individuals

\begin{tabular}{lcccc}
\hline PWA & Listening & Speaking & Reading & Writing \\
\hline 1 & 122 & 254 & 122 & 90 \\
2 & 126 & 231 & 118 & 94 \\
3 & 112 & 155 & 91 & 86 \\
4 & 127 & 235 & 126 & 90 \\
5 & 119 & 216 & 113 & 64 \\
6 & 119 & 214 & 110 & 63 \\
7 & 88 & 84 & 57 & 58 \\
8 & 36 & 0 & 46 & 22 \\
9 & 109 & 198 & 93 & 51 \\
10 & 108 & 157 & 107 & 16 \\
11 & 126 & 212 & 120 & 88 \\
12 & 123 & 224 & 122 & 84 \\
13 & 122 & 186 & 114 & 50 \\
14 & 84 & 113 & 54 & 28 \\
15 & 89 & 163 & 92 & 52 \\
Mean & 107.33 & 176.13 & 99 & 62.4 \\
\hline
\end{tabular}


Appendix 5. CAT Scores for LHD Individuals

\begin{tabular}{lcccc}
\hline LHD & Listening & Speaking & Reading & Writing \\
\hline 1 & 136 & 256 & 132 & 104 \\
2 & 136 & 267 & 132 & 116 \\
3 & 136 & 282 & 132 & 102 \\
4 & 136 & 278.5 & 132 & 114 \\
5 & 136 & 289 & 132 & 109 \\
6 & 138 & 299 & 132 & 109 \\
7 & 132 & 247 & 126 & 98 \\
8 & 140 & 270 & 132 & 121 \\
9 & 136 & 275 & 132 & 91 \\
10 & 138 & 284 & 132 & 135 \\
11 & 134 & 279 & 132 & 102 \\
12 & 134 & 271 & 132 & 102 \\
13 & 136 & 277 & 132 & 100 \\
14 & 140 & 290 & 132 & 104 \\
15 & 140 & 293 & 130 & 110 \\
Mean & 136.53 & 277.17 & 131.47 & 107.8 \\
\hline
\end{tabular}


Appendix 6. T and Z scores for PWA individuals: T (Z-scores)

\begin{tabular}{|c|c|c|c|c|c|c|c|c|}
\hline PWA & $\begin{array}{c}\text { Auditory } \\
\text { Comprehension }\end{array}$ & $\begin{array}{c}\text { Visual } \\
\text { Comprehension }\end{array}$ & Repetition & Naming & $\begin{array}{c}\text { Spoken Picture } \\
\text { Description }\end{array}$ & $\mathrm{gg}$ & Wri & $\begin{array}{l}\text { Written Picture } \\
\text { Description }\end{array}$ \\
\hline 1 & 62) & $2(1.16-1.20)$ & $(0.9-0.93)$ & $68(1.7-1.81)$ & & & & \\
\hline 2 & $2(1.16-1.20)$ & $60(0.98-1.01)$ & & & & & & \\
\hline 3 & $62(1.16-1.20)$ & $65(1.44-1.51)$ & $52(0.4-0.6)$ & $59(0.9-0.93)$ & $48(-0.19--0.21)$ & $8(-0.19--0.21)$ & & \\
\hline 4 & 58 (0.79-0.82) & $65(1.44-1.51)$ & $61(1.10)$ & $63(1.26-1.31)$ & $58(0.79-0.82)$ & & $62(1.16-1.20)$ & \\
\hline 5 & $62(1.16-1.20)$ & $60(0.98-1.01)$ & $54(0.4-0.42)$ & $62(1.16-1.20)$ & $60(0.98-1.01)$ & $58(0.79-0.82)$ & $53(0.3-$ & \\
\hline 6 & $53(0.3-0.31)$ & $58(0.79-0.82)$ & & & & & & \\
\hline 7 & $53(0.3-0.31)$ & $50(0.1--0.1)$ & $47(-0.30--0.31)$ & $49(-0.9--0.11)$ & $47(-0.30--0.31)$ & $45(-0.49--0.50)$ & 51 (0.09 & $55(0.49-0.50)$ \\
\hline 8 & $43(-0.66--0.69)$ & $53(0.3-0.31)$ & & & & & & \\
\hline 9 & $53(0.3-0.31)$ & $53(0.3-0.31)$ & & $57(0.66-0.69)$ & & & $50(0.1--0.1)$ & \\
\hline 10 & $53(0.3-0.31)$ & $53(0.3-0.31)$ & $53(0.3-0.31)$ & $50(0.1--0.1)$ & $48(-0.19--0.21)$ & $59(0.9-0.93)$ & $43(-0.66--0.69)$ & 53 (0.3- \\
\hline 11 & $60(0.98-1.01)$ & $65(1.44$ & & & & & & \\
\hline 12 & 63 (1.26-1.31) & $70(2.0)$ & $56(0.6-0.62)$ & $70(2.16)$ & $51(0.09-0.11)$ & & & $61(1.10)$ \\
\hline 13 & $56(0.6-0.62)$ & $56(0.6-0.62)$ & $59(0.9-0.93)$ & $52(0.4-0.6)$ & $50(0.1--0.1)$ & $62(1.16-1.20)$ & $51(0.09-0.11)$ & $52(0.4-0.6)$ \\
\hline 14 & $45(-0.49--0.50)$ & $49(-0.9--0.11)$ & $49(-0.9--0.11)$ & $51(0.09-0.11)$ & $52(0.4-0.6)$ & $45(-0.49--0.50)$ & $46(-0.40--0.42)$ & $42(-0.79--0.82)$ \\
\hline$\checkmark$ & $52(0.4-0.6)$ & $51(0.09-0.11)$ & $48(-0.19--0.21)$ & $57(0.66-0.69)$ & $52(0.4-0.6)$ & $56(0.6-0.62)$ & $69(1.82-1.95)$ & $55(0.49-0.50)$ \\
\hline
\end{tabular}


Appendix 7. T and Z scores of LHD: T (Z-scores)

\begin{tabular}{lllllllll}
\hline LHD & $\begin{array}{c}\text { Auditory } \\
\text { Comprehension }\end{array}$ & \multicolumn{2}{c}{$\begin{array}{c}\text { Visual } \\
\text { Comprehension }\end{array}$} & Repetition & Naming & $\begin{array}{c}\text { Spoken Picture } \\
\text { Description }\end{array}$ & Reading & $\begin{array}{c}\text { Writing } \\
\text { Written Picture } \\
\text { Description }\end{array}$ \\
\hline 1 & $75(2.5)$ & $73(2.33)$ & $72(2.16)$ & $68(1.7-1.81)$ & $62(1.16-1.20)$ & $71(2.1)$ & $62(1.16-1.20)$ & $73(2.33)$ \\
2 & $75(2.5)$ & $73(2.33)$ & $72(2.16)$ & $65(1.44-1.51)$ & $63(1.26-1.31)$ & $71(2.1)$ & $64(1.38-1.44)$ & $75(2.5)$ \\
3 & $66(1.60-1.69)$ & $73(2.33)$ & $75(2.5)$ & $67(1.60-1.69)$ & $75(2.5)$ & $71(2.1)$ & $69(1.82-1.95)$ & $73(2.33)$ \\
4 & $75(2.5)$ & $75(2.5)$ & $75(2.5)$ & $75(2.5)$ & $67(1.60-1.69)$ & $75(2.5)$ & $75(2.5)$ & $75(2.5)$ \\
\hline 5 & $66(1.60-1.69)$ & $75(2.5)$ & $75(2.5)$ & $67(1.60-1.69)$ & $63(1.26-1.31)$ & $76(2.5)$ & $75(2.5)$ & $74(2.4)$ \\
\hline 6 & $75(2.5)$ & $75(2.5)$ & $67(1.60-1.69)$ & $71(2.1)$ & $75(2.5)$ & $75(2.5)$ & $75(2.5)$ & $74(2.4)$ \\
7 & $58(0.79-0.82)$ & $69(1.82-1.95)$ & $75(2.5)$ & $62(1.16-1.20)$ & $62(1.16-1.20)$ & $64(1.38-1.44)$ & $75(2.5)$ & $67(1.60-1.69)$ \\
\hline 8 & $75(2.5)$ & $75(2.5)$ & $75(2.5)$ & $67(1.60-1.69)$ & $67(1.60-1.69)$ & $75(2.5)$ & $75(2.5)$ & $75(2.5)$ \\
9 & $62(1.16-1.20)$ & $75(2.5)$ & $75(2.5)$ & $68(1.7-1.81)$ & $65(1.44-1.51)$ & $75(2.5)$ & $75(2.5)$ & $62(1.16-1.20)$ \\
10 & $75(2.5)$ & $75(2.5)$ & $75(2.5)$ & $69(1.82-1.95)$ & $70(2.0)$ & $75(2.5)$ & $75(2.5)$ & $75(2.5)$ \\
11 & $75(2.5)$ & $75(2.5)$ & $60(0.98-1.01)$ & $71(2.1)$ & $71(2.1)$ & $75(2.5)$ & $61(1.10)$ & $72(2.16)$ \\
12 & $75(2.5)$ & $75(2.5)$ & $75(2.5)$ & $75(2.5)$ & $75(2.5)$ & $75(2.5)$ & $63(1.26-1.31)$ & $75(2.5)$ \\
13 & $75(2.5)$ & $75(2.5)$ & $72(2.16)$ & $71(2.1)$ & $65(1.44-1.51)$ & $75(2.5)$ & $58(0.79-0.82)$ & $73(2.33)$ \\
14 & $66(1.60-1.69)$ & $65(1.44-1.51)$ & $75(2.5)$ & $70(2.16)$ & $74(2.4)$ & $75(2.5)$ & $59(0.9-0.93)$ & $75(2.5)$ \\
15 & $52(0.4-0.6)$ & $51(0.09-0.11)$ & $48(-0.19--0.21)$ & $57(0.66-0.69)$ & $52(0.4-0.6)$ & $56(0.6-0.62)$ & $69(1.82-1.95)$ & $55(0.49-0.50)$ \\
\hline
\end{tabular}

